\title{
$\beta$-Adrenoceptor subtypes and cAMP role in adrenaline- and noradrenaline-induced relaxation in the rat thoracic aorta
}

\author{
Shunsuke SHIINA ${ }^{1}$, Ayaka KANEMURA ${ }^{1}$, Chihiro SUZUKI ${ }^{1}$, Fumiko YAMAKI ${ }^{1}$, \\ Keisuke OBARA ${ }^{1}$, Daisuke $\mathrm{CHINO}^{1,2}$, and Yoshio TANAKA ${ }^{1 *}$ \\ ${ }^{1}$ Department of Chemical Pharmacology, Faculty of Pharmaceutical Sciences, Toho University, \\ 2-2-1 Miyama, Funabashi-City, Chiba 274-8510, Japan \\ ${ }^{2}$ Department of Pharmacotherapy, Faculty of Pharmaceutical Sciences, Nihon Pharmaceutical \\ University, 10281 Komuro, Ina-machi, Kita-Adachi-gun, Saitama 362-0806, Japan
}

Submitted March 9, 2017; accepted in final from January 21, 2018

\begin{abstract}
Object We identified the $\beta$-adrenoceptor ( $\beta$-AR) subtypes responsible for the relaxant responses to adrenaline (AD) and noradrenaline (NA) in the rat thoracic aorta and examined the role of cAMP which is involved in these relaxant responses. Methods The effects of $\beta$-AR antagonists or the adenylyl cyclase inhibitor SQ 22,536 on AD- and NA-induced relaxant responses in phenylephrine-induced contraction and increases in cAMP levels were examined in isolated, endothelium-denuded rat thoracic aorta segments. Results AD-induced relaxation was completely suppressed by propranolol $\left(10^{-7} \mathrm{M}\right)$ or by ICI-118,551 $\left(10^{-8} \mathrm{M}\right)$ plus atenolol $\left(10^{-6}\right.$ $\mathrm{M})$, and was also very strongly inhibited by ICI-118,551 $\left(10^{-8} \mathrm{M}\right)$ alone. AD $\left(10^{-5} \mathrm{M}\right)$ increased tissue cAMP levels by approximately 1.9-fold compared with that in non-stimulated aortic tissue, but did not significantly increase cAMP levels in the presence of ICI-118,551 $\left(10^{-8} \mathrm{M}\right)$ or SQ 22,536 $\left(10^{-4} \mathrm{M}\right)$. AD-induced relaxation was strongly suppressed by SQ 22,536 $\left(10^{-4} \mathrm{M}\right)$. NA-induced relaxation was almost completely suppressed by atenolol $\left(10^{-6} \mathrm{M}\right)$ plus ICI-118,551 $\left(10^{-8} \mathrm{M}\right)$ although it was hardly affected by ICI-118,551 $\left(10^{-8} \mathrm{M}\right)$ alone. NA $\left(10^{-5} \mathrm{M}\right)$ increased tissue cAMP levels by approximately 2.2-fold compared with that in non-stimulated aortic tissue, but did not significantly increase cAMP levels in the presence of atenolol $\left(10^{-6} \mathrm{M}\right)$ or SQ 22,536 $\left(10^{-4} \mathrm{M}\right)$. NA-induced relaxation was strongly suppressed by SQ 22,536 $\left(10^{-4} \mathrm{M}\right)$. Conclusion In rat thoracic aorta, AD- and NA-induced relaxations, which are both strongly dependent on increased tissue cAMP levels, are mainly mediated through $\beta_{2}$-and $\beta_{1}$-adrenoceptors respectively.
\end{abstract}

Key words: catecholamines, $\beta$-adrenoceptor $(\beta$-AR), rat thoracic aorta, relaxation, tissue cyclic AMP level

Corresponding author: Yoshio Tanaka, Ph.D., Department of Chemical Pharmacology, Faculty of Pharmaceutical Sciences, Toho University, 2-2-1 Miyama, Funabashi-City, Chiba 274-8510, Japan Phone: +81-47-472-1419 Fax: +81-47-472-1419 e-mail: yotanaka@phar.toho-u.ac.jp (C2018 The Japan Society of Smooth Muscle Research 


\section{Introduction}

The $\beta$-adrenoceptor ( $\beta$-AR) is a drug receptor which is one of the family of $G$ protein-coupled receptors (GPCRs) $(1,2) . \beta$-AR is widely distributed in different smooth muscles, including blood vessels, and its physiological role is considered to include inhibitory regulation of smooth muscle tone. In particular, $\beta$-AR is thought to play an important role in attenuating contraction responses mediated by $\alpha_{1}$-AR in vascular smooth muscle $(3,4)$.

The $\beta$-AR subtype of vascular smooth muscle was initially classified as the $\beta_{2}$-AR (5). However, the presence of $\beta_{1}$-AR in addition to $\beta_{2}$-AR has been reported in vascular smooth muscle based on pharmacological studies with subtype-selective $\beta$-AR antagonists, receptor binding studies with radioactive ligands for $\beta$-AR, and mRNA expression experiments using RT-PCR and other techniques $(6,7)$. Furthermore, pharmacological and biochemical evidence has demonstrated the presence of $\beta_{3}$-AR, first reported in adipocytes (8-10). In addition, a possible contribution by cAMP-independent mechanisms in the $\beta_{3}$-AR-mediated blood vessel relaxation has been suggested (11).

However, in most studies to date, experiments were designed using the synthetic catecholamine isoprenaline, and studies using endogenous $\beta$-AR agonists such as adrenaline (AD) and noradrenaline (NA) are limited $(12,13)$. However, in order to understand the physiological role (significance) of endogenous $\beta$-AR agonists and $\beta$-ARs, and the suppressive mechanisms by which $\beta$-ARs regulate the contractile and relaxant functions of blood vessels, the target subtypes for endogenous $\beta$-AR agonists and the intracellular mechanisms underlying these agonist-mediated blood vessel relaxations must be elucidated.

Therefore, in this study, we focused on AD and NA, the most fundamental endogenous catecholamines acting as endogenous agonists for $\beta$-AR, to pharmacologically determine the $\beta$-AR subtype that mediates relaxant responses in the rat aorta and to elucidate the underlying mechanisms involved in relation to changes in tissue cAMP levels.

\section{Materials and Methods}

\section{Animals}

Male Wistar rats (8-9 weeks old, weighing 180-230 g; Sankyo Labo Service Corporation, Tokyo, Japan) were housed under controlled conditions (lights on: 8 am, lights off: $8 \mathrm{pm}$; temperature: $20-22^{\circ} \mathrm{C}$; relative air humidity: $50 \pm 5 \%$ ). Food and water were available to all animals ad libitum, and only healthy rats were used for experiments. This study was approved by the Toho University Animal Care and User Committee (approval number: 15-51-294, accredited on May 22, 2015; approval number: 16-52-294, accredited on May 16, 2016) and conducted in accordance with the User Guidelines of the Laboratory Animal Center of the Faculty of Pharmaceutical Sciences, Toho University.

\section{Preparation of aortic vascular beds}

The rats were anesthetized with isoflurane (inhalation) and exsanguinated from a carotid artery. A section of thoracic aorta between the aortic arch and the diaphragm was quickly removed and immersed in a modified Krebs-Henseleit solution containing $118 \mathrm{mM} \mathrm{NaCl}, 4.75 \mathrm{mM} \mathrm{KCl}, 2.54 \mathrm{mM} \mathrm{CaCl}_{2}, 1.20 \mathrm{mM} \mathrm{MgSO}_{4}, 1.19 \mathrm{mM}$ $\mathrm{NaH}_{2} \mathrm{PO}_{4}, 25 \mathrm{mM} \mathrm{NaHCO}$, and $11 \mathrm{mM}$ D-(+)-glucose. The aorta was cleaned of loosely adhering fat and connective tissue under a dissecting microscope, cut into spiral segments approximately $2 \mathrm{~mm}$ in width and $20 \mathrm{~mm}$ in length, and endothelium-free preparations were produced by gently rubbing the intimal surface with 
filter paper. Two spiral segments were prepared from each rat, one of which was used for control recording in the absence of any inhibitors and the other for examining the effects of $\beta$-AR antagonists or adenylyl cyclase inhibitor SQ 22,536. However, for recording NA-induced relaxation, the region close to the diaphragm was used; control and inhibitor treatment recordings were therefore carried out using two spiral segments prepared from different rats.

\section{Recording of isometric tension changes}

The spiral aortic segments were mounted under an optimal resting tension of $1.0 \mathrm{~g}$ in a 20 -ml organ bath containing modified Krebs-Henseleit solution aerated with $95 \% \mathrm{O}_{2}$ and $5 \% \mathrm{CO}_{2}$, and maintained at $35.0 \pm 0.5^{\circ} \mathrm{C}$ $(\mathrm{pH}=7.4)$. Tension changes in the muscle preparation were isometrically measured using a force-displacement transducer (TB-612T; Nihon Kohden Corporation, Tokyo, Japan) connected to an amplifier (AP-621G; Nihon Kohden) and recorded on a Windows PC through an A/D converter (Power Lab/4sp; ADInstruments Japan Inc., Nagoya City, Aichi, Japan) and associated software (Chart 7 for Windows; ADInstruments Japan Inc.).

Spiral preparations were equilibrated for 60-90 min prior to the first phenylephrine (Phe)-induced contraction, during which time the modified Krebs-Henseleit solution was replaced every 20 min with fresh solution. After the equilibration period, the aortic preparation was contracted 2-3 times with $10^{-7} \mathrm{M}$ Phe to confirm that the preparation generated a normal level of contraction. At the first Phe-induced contraction, the preparation was challenged with acetylcholine ( $\left.\mathrm{ACh}, 10^{-5} \mathrm{M}\right)$ to verify the functional absence of endothelium. An aortic preparation in which ACh-induced relaxation was not observed was regarded as an endothelium-denuded preparation. Each experiment was carried out in the presence of indomethacin $\left(3 \times 10^{-6} \mathrm{M}\right)$ to eliminate the possible effects of endogenous prostaglandins (PGs) produced in blood vessel tissues.

\section{Assessment of the effects of $\beta-A R$ antagonists on $A D$ - and NA-induced relaxation}

After the aortic preparation had been contracted 2-3 times with $10^{-7} \mathrm{M}$ Phe, as described above, and had fully recovered by washing in fresh solution, the preparation was again contracted using $10^{-5} \mathrm{M}$ Phe. When the Phe $\left(10^{-5} \mathrm{M}\right)$-induced contraction reached a steady-state level, which usually occurred 20-30 min after the application of Phe, AD or NA was cumulatively applied to the bath solution to determine their concentrationresponse relationships, which were regarded as their control responses. In order to examine the effects of various $\beta$-AR antagonists or the adenylyl cyclase inhibitor SQ 22,536 on AD- or NA-induced relaxation, these agents were applied to the bath solution $20 \mathrm{~min}$ before the administration of $10^{-5} \mathrm{M}$ Phe (40-50 min before the cumulative application of $\mathrm{AD}$ or $\mathrm{NA}$ ) and remained until the maximum relaxant response to $\mathrm{AD}$ or NA was obtained.

The $\beta$-AR antagonists used in the present study were propranolol (a non-selective $\beta_{1^{-}}, \beta_{2}$-AR antagonist), atenolol (a selective $\beta_{1}$-AR antagonist), and ICI-118,551 (a selective $\beta_{2}$-AR antagonist).

\section{Determination of tissue cAMP content}

Spiral segments ( $2 \mathrm{~mm}$ in width and $20 \mathrm{~mm}$ in length) were prepared from a 15 - $\mathrm{mm}$-long segment of thoracic aorta, as described for the tension recording studies. In this series of experiments, the endothelium was removed with filter paper and each preparation was incubated in an organ bath containing normal Tyrode's solution (20 ml) containing $158.3 \mathrm{mM} \mathrm{NaCl}, 4.0 \mathrm{mM} \mathrm{KCl}, 2.0 \mathrm{mM} \mathrm{CaCl}_{2}, 1.05 \mathrm{mM} \mathrm{MgCl}_{2}, 0.42 \mathrm{mM} \mathrm{NaH}_{2} \mathrm{PO}_{4}$, $10.0 \mathrm{mM} \mathrm{NaHCO}_{3}$, and $5.6 \mathrm{mM} \mathrm{D}-(+)$-glucose, and continuously aerated with $95 \% \mathrm{O}_{2}$ and $5 \% \mathrm{CO}_{2}$ and maintained at $35.0 \pm 0.5^{\circ} \mathrm{C}(\mathrm{pH}=7.4)$. After a 60 -min incubation, the artery segments were exposed to $\mathrm{AD}\left(10^{-5} \mathrm{M}\right)$ or NA $\left(10^{-5} \mathrm{M}\right)$ for $5 \mathrm{~min}$. $\beta$-AR antagonists or SQ 22,536 were applied to the bath solution 40 min before the 
application of $\mathrm{AD}\left(10^{-5} \mathrm{M}\right)$ or NA $\left(10^{-5} \mathrm{M}\right)$. At the end of the experiment, tissues were rapidly frozen in liquid $\mathrm{N}_{2}$ to terminate the reaction and crushed using a frozen cell crusher apparatus (Cryo-Press ${ }^{\mathrm{TM}}$; Microtec Co., Ltd., Funabashi City, Chiba, Japan). The resulting crushed powders were mixed with 6\% trichloroacetic acid (TCA) solution containing 3-isobutyl-1-methylxanthine (IBMX; $5 \times 10^{-4} \mathrm{M}$; a phosphodiesterase inhibitor) for $30 \mathrm{~s}$ using a vortex mixer. The suspension was incubated for $60 \mathrm{~min}$ at $4^{\circ} \mathrm{C}$ and then centrifuged at 2,000 $\times g$ for $15 \mathrm{~min}$ at $4^{\circ} \mathrm{C}$. The supernatant fractions and tissue pellets were used for the measurement of cAMP and protein content, respectively. The cAMP in the supernatant was extracted four times with water-saturated ether to remove TCA under acidic conditions $(\mathrm{HCl})$ and then lyophilized. cAMP levels were measured using an enzyme immunoassay system (cAMP, Biotrak EIA System; GE Healthcare UK Ltd., Buckinghamshire, UK). Tissue pellets were dissolved in $1 \mathrm{ml}$ of $1 \mathrm{M} \mathrm{NaOH}$ for protein determination by the bicinchoninic acid (BCA) method using a Pierce ${ }^{\mathrm{TM}}$ BCA protein assay kit (Thermo Scientific, Rockford, IL, USA). The cAMP content was expressed as picomoles per milligram of sample protein ( $\mathrm{pmol} / \mathrm{mg}$ protein).

In our study, the tissue cAMP contents were measured in the absence of Phe and indomethacin according to previous studies wherein arterial cAMP contents were measured in their absence, whereas the relaxant responses were measured in their presence (14).

\section{Drugs}

The following drugs were used: (-)-phenylephrine hydrochloride, (-)-isoproterenol hydrochloride (isoprenaline), (-)-adrenaline-(+)-bitartrate salt, $( \pm)$-propranolol hydrochloride, $( \pm)$-atenolol, and indomethacin (Sigma-Aldrich Co., St. Louis, MO, USA); (土)-1-[2,3-(dihydro-7-methyl-1H-inden-4-yl)oxy]-3-[(1-methylethyl)amino]-2-butanol hydrochloride (ICI-118,551) (Tocris Bioscience, Ellisville, MO, USA); acetylcholine chloride (Daiichi Sankyo Company Ltd., Tokyo, Japan); and (R)-(-)-noradrenaline hydrogen tartrate monohydrate (Wako Pure Chemical Industries, Osaka, Japan). All other chemicals were commercially available and of reagent grade. Atenolol was dissolved in $0.1 \mathrm{~N} \mathrm{HCl}$ to produce a stock solution of $10^{-2} \mathrm{M}$. Indomethacin was dissolved in $100 \%$ ethanol to produce a stock solution of $10^{-2} \mathrm{M}$. All other drugs were prepared as aqueous solutions and diluted with distilled water. Drugs were added directly to the organ bath and expressed in molar concentration $(\mathrm{M})$ in the bath medium.

\section{Data analysis}

The extent of relaxation induced by $\beta$-AR agonists (AD and NA) was calculated with respect to the basal tension $\left(100 \%\right.$ relaxation) prior to the application of Phe $\left(10^{-5} \mathrm{M}\right)$ and the steady-state tension level prior to the application of each relaxant ( $0 \%$ relaxation).

$\beta$-AR agonist potencies were expressed as $\mathrm{p} D_{2}\left(\mathrm{pEC}_{50}\right)$ values (the negative logarithm of the effective agonist concentration that produces a response which is $50 \%$ of the maximum response). Data were plotted as a function of vasorelaxant concentration and fitted to the equation:

$$
E=E_{\max } \times A^{n_{\mathrm{H}}} /\left(\mathrm{EC}_{50} n_{\mathrm{H}}+A^{n_{\mathrm{H}}}\right)
$$

where $E$ is the \% relaxation at a given concentration, $E_{\max }$ is the maximum response, $A$ is the agonist (relaxant) concentration, $n_{\mathrm{H}}$ is the slope function, and $\mathrm{EC}_{50}$ is the effective agonist concentration that produced a 50\% response. Curve-fitting was performed using GraphPad Prism ${ }^{\mathrm{TM}}$ (Version 6.07; GraphPad Software, Inc., San Diego, CA, USA). The $\mathrm{EC}_{50}$ values were converted to logarithmic values $\left(\mathrm{p} D_{2},-\log \mathrm{E}_{50}\right)$ for statistical analysis.

Data are presented as mean values \pm S.E.M., and $n$ refers to the number of preparations. The probability 

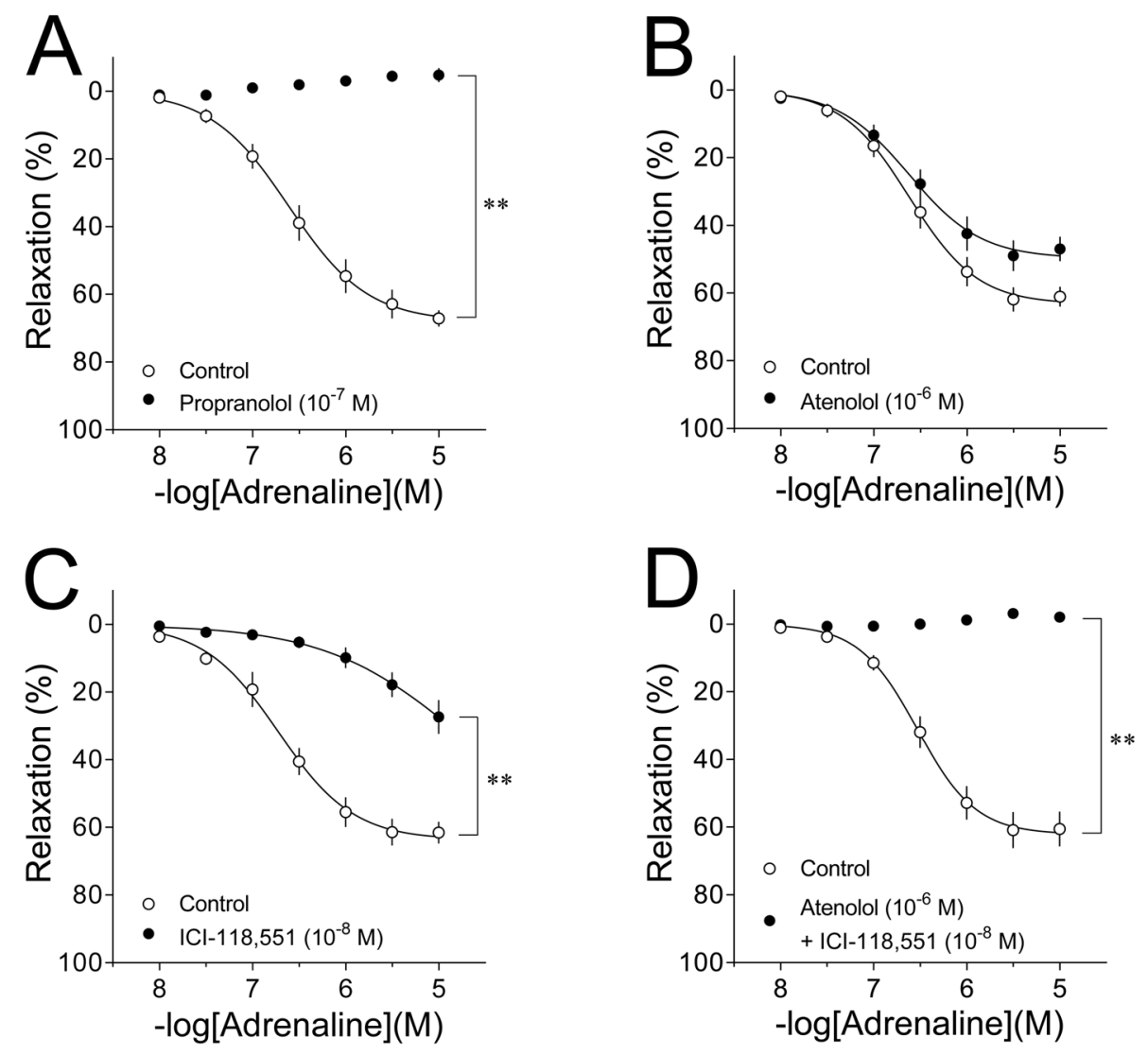

Fig. 1. Effect of various $\beta-A R$ antagonists on adrenaline (AD)-induced relaxation in segments of the rat thoracic aorta. A: Effects of propranolol $\left(10^{-7} \mathrm{M}\right)(n=5$ for each). B: Effects of atenolol $\left(10^{-6} \mathrm{M}\right)\left(n=8\right.$ for each). C: Effects of ICI-118,551 $\left(10^{-8} \mathrm{M}\right)(n=5$ for each $)$. D: Effects of atenolol $\left(10^{-6} \mathrm{M}\right)+\mathrm{ICI}-118,551\left(10^{-8} \mathrm{M}\right)\left(n=5\right.$ for each). ${ }^{* *} P<0.01$ : vs. control.

$(P)$ of the difference between two sets of values being due to chance was evaluated using GraphPad Prism ${ }^{\mathrm{TM}}$ with two-way analysis of variance (ANOVA) or one-way ANOVA followed by Dunnett's multiple comparison tests. Differences with a $P$ value of less than 0.05 were considered to be statistically significant.

\section{Results}

\section{$\beta$-AR subtypes that mediate $A D$-induced relaxation}

Figure 1 shows the effects of $\beta$-AR antagonists on AD-induced relaxation in segments of the rat thoracic aorta. AD-induced relaxation was completely inhibited by propranolol $\left(10^{-7} \mathrm{M}\right)($ Fig. 1A) but was not significantly affected by the selective $\beta_{1}$-AR antagonist atenolol $\left(10^{-6} \mathrm{M}\right)$ (Fig. 1B). In contrast, AD-induced relaxation was significantly suppressed by the selective $\beta_{2}$-AR antagonist ICI-118,551 $\left(10^{-8} \mathrm{M}\right)$, although the degree of inhibition was weaker than that produced by propranolol $\left(10^{-7} \mathrm{M}\right)$ (Fig. 1C). AD-induced relaxation was completely suppressed by the combination of atenolol $\left(10^{-6} \mathrm{M}\right)$ plus ICI-118,551 $\left(10^{-8} \mathrm{M}\right)$ (Fig. 1D).

\section{Role of CAMP in $A D$-induced relaxation}

Figure 2 shows the changes in tissue cAMP levels induced by AD in segments of the rat thoracic aorta and the effects of the $\beta$-AR antagonists and SQ 22,536 on these changes. AD $\left(10^{-5} \mathrm{M}\right)$ increased the tissue cAMP level by 1.9-fold, from $1.4 \pm 0.2$ to $2.6 \pm 0.3 \mathrm{pmol} / \mathrm{mg}$ protein $(n=5, P<0.01)$ (Fig. 2). $\mathrm{AD}\left(10^{-5} \mathrm{M}\right)$ also signifi- 


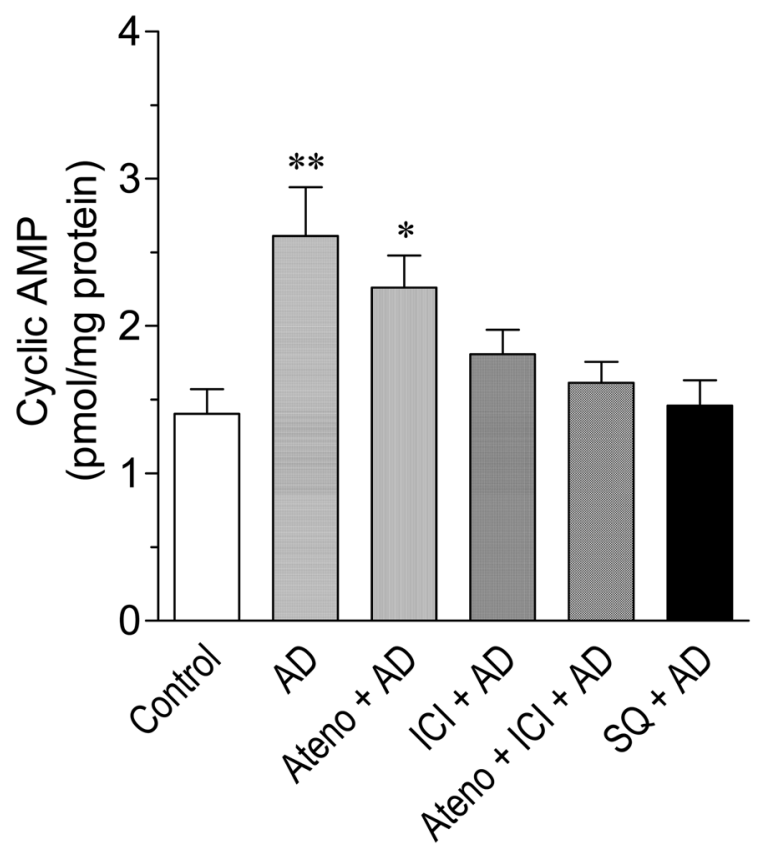

Fig. 2. AD-mediated increase in tissue cAMP content in segments of the rat aorta and the inhibitory effects of $\beta$-AR antagonists and SQ 22,536 on this increase. AD: adrenaline $\left(10^{-5} \mathrm{M}\right)$; Ateno: atenolol $\left(10^{-6} \mathrm{M}\right)$; ICI: ICI-118,551 $\left(10^{-8} \mathrm{M}\right)$; SQ: SQ 22,536 $\left(10^{-4} \mathrm{M}\right) . * P<0.05,{ }^{* *} P<0.01$ : vs. control (cAMP content in unstimulated aorta). $n=5$ for each.

cantly increased tissue cAMP levels in the presence of atenolol $\left(10^{-6} \mathrm{M}\right)$, but only to approximately $70 \%$ of the increase observed in the absence of atenolol. In the presence of ICI-118,551 $\left(10^{-8} \mathrm{M}\right)$, AD did not significantly increase tissue cAMP levels compared with control (non-stimulated level) but levels were still increased by approximately $40 \%$. AD $\left(10^{-5} \mathrm{M}\right)$ had no effect on tissue cAMP levels in the presence of both atenolol $\left(10^{-6} \mathrm{M}\right)$ and ICI-118,551 $\left(10^{-8} \mathrm{M}\right)$, or in the presence of SQ 22,536 $\left(10^{-4} \mathrm{M}\right)$ alone.

Figure 3A shows that SQ 22,536 $\left(10^{-4} \mathrm{M}\right)$ treatment significantly suppressed AD-induced relaxation to about half of the response observed in the absence of SQ 22,536. Specifically, the relaxation induced by AD $\left(10^{-5} \mathrm{M}\right)$ was suppressed from $65.9 \pm 6.0 \%$ to $31.7 \pm 5.7 \%$ (52\% inhibition, $48 \%$ of control). In the presence of atenolol $\left(10^{-6} \mathrm{M}\right)$, however, AD-induced relaxation was more strongly suppressed by SQ 22,536 $\left(10^{-4} \mathrm{M}\right)$ than in the absence of atenolol (Fig. 3B). Specifically, the relaxation induced by AD $\left(10^{-5} \mathrm{M}\right)$ was suppressed from $42.6 \pm 6.1 \%$ to $10.5 \pm 2.4 \%$ by SQ 22,536 , approximately $25 \%$ of the level observed in the absence of SQ 22,536 ( $75 \%$ inhibition).

\section{$\beta-A R$ subtypes that mediate $N A$-induced relaxation}

Figure 4 shows the effects of ICI-118,551 and atenolol on NA-induced relaxation of in segments of the rat thoracic aorta. NA-induced relaxation was not significantly affected by ICI-118,551 (10-8 M) (Fig. 4A). NAinduced relaxation was almost completely suppressed, however, by combined treatment with atenolol $\left(10^{-6} \mathrm{M}\right)$ and ICI-118,551 $\left(10^{-8} \mathrm{M}\right)$, although the relaxation induced by high concentration $\left(10^{-5} \mathrm{M}\right)$ of NA was maintained partially (Fig. 4B).

\section{Role of CAMP in NA-induced relaxation}

Figure 5 shows the changes in tissue cAMP levels induced by NA in segments of the rat thoracic aorta and the effects of $\beta$-AR antagonists and SQ 22,536 on these changes. NA $\left(10^{-5} \mathrm{M}\right)$ increased the tissue cAMP 

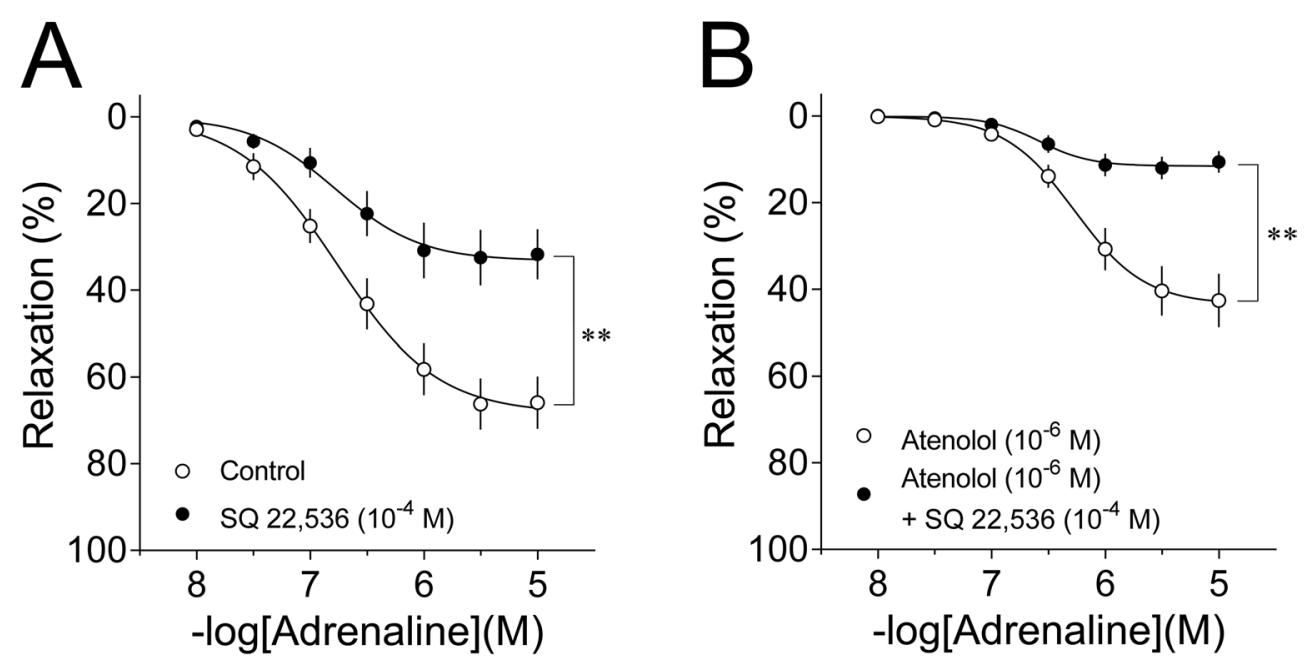

Fig. 3. Effects of SQ 22,536 on AD-induced relaxation in segments of the rat aorta. A: Effects of SQ $22,536\left(10^{-4} \mathrm{M}\right)$ on $\mathrm{AD}$-induced relaxation in the absence of atenolol ( $n=5$ for each). B: Effects of SQ 22,536 $\left(10^{-4} \mathrm{M}\right)$ on AD-induced relaxation in the presence of atenolol $\left(10^{-6} \mathrm{M}\right)(n=5$ for each). ${ }^{* *} P<0.01$ vs. control or atenolol $\left(10^{-6} \mathrm{M}\right)$.
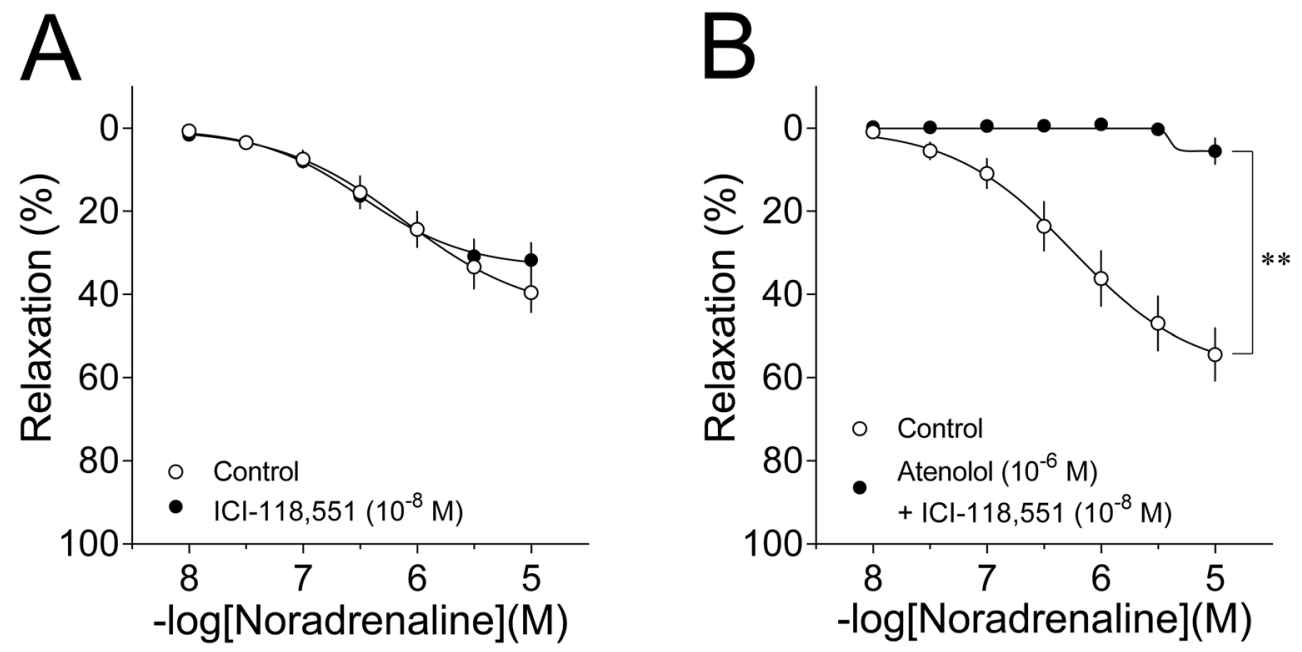

Fig. 4. Effect of ICI-118,551 or atenolol plus ICI-118,551 on noradrenaline (NA)-induced relaxation in segments of the rat thoracic aorta. A: Effects of ICI-118,551 $\left(10^{-8} \mathrm{M}\right)(n=6$ for each). B: Effects of atenolol $\left(10^{-6} \mathrm{M}\right)+\mathrm{ICI}-118,551\left(10^{-8} \mathrm{M}\right)(n=5$ for each $) . * * P<0.01$ vs. control.

level by 2.2 -fold, from $1.2 \pm 0.2$ to $2.6 \pm 0.2 \mathrm{pmol} / \mathrm{mg}$ protein ( $n=8$ for control and $n=9$ for NA, $P<0.01)$. In the presence of atenolol $\left(10^{-6} \mathrm{M}\right)$, NA $\left(10^{-5} \mathrm{M}\right)$ increased tissue cAMP levels by approximately $20 \%$ compared with unstimulated levels, and this effect was not statistically significant. In the presence of ICI-118,551 $\left(10^{-8}\right.$ M), NA $\left(10^{-5} \mathrm{M}\right)$ increased tissue cAMP levels by approximately $35 \%$ compared with unstimulated levels, although again this effect was not statistically significant. NA $\left(10^{-5} \mathrm{M}\right)$ did not increase tissue cAMP levels in the presence of both atenolol $\left(10^{-6} \mathrm{M}\right)$ and ICI-118,551 $\left(10^{-8} \mathrm{M}\right)$. Even in the presence of SQ 22,536 $\left(10^{-4} \mathrm{M}\right)$, NA $\left(10^{-5} \mathrm{M}\right)$ had no effect on tissue cAMP levels.

NA-induced relaxation was significantly and strongly suppressed by SQ $22,536\left(10^{-4} \mathrm{M}\right)$ treatment. Specifically, the relaxation induced by $10^{-5} \mathrm{M} N A$ was suppressed from $43.6 \pm 3.4 \%$ to $18.8 \pm 8.1 \%$, approximately $57 \%$ inhibition ( $43 \%$ relaxation vs. control) (Fig. 6). 


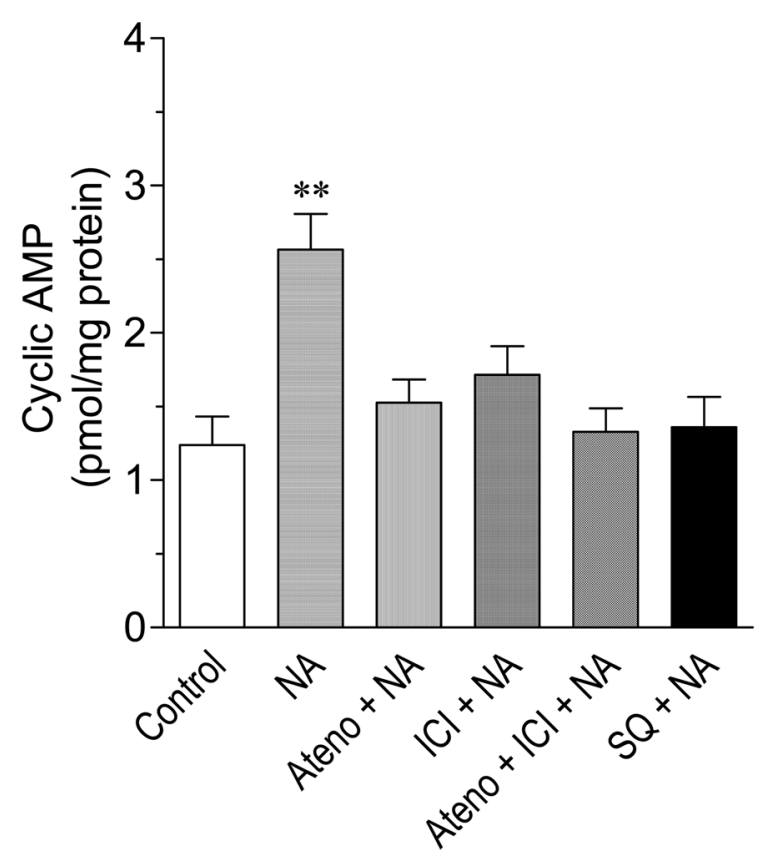

Fig. 5. NA-mediated increase in tissue cAMP content in segments of the rat aorta and the inhibitory effects of $\beta$-AR antagonists and SQ 22,536 on this increase. NA: noradrenaline $\left(10^{-5} \mathrm{M}\right)$; Ateno: atenolol $\left(10^{-6} \mathrm{M}\right)$; ICI: ICI-118,551 $\left(10^{-8} \mathrm{M}\right)$; SQ: SQ 22,536 $\left(10^{-4} \mathrm{M}\right) . * * P<0.01$ : vs. control (cAMP content in unstimulated aorta). $n=9$ for NA and $n=8$ for others.

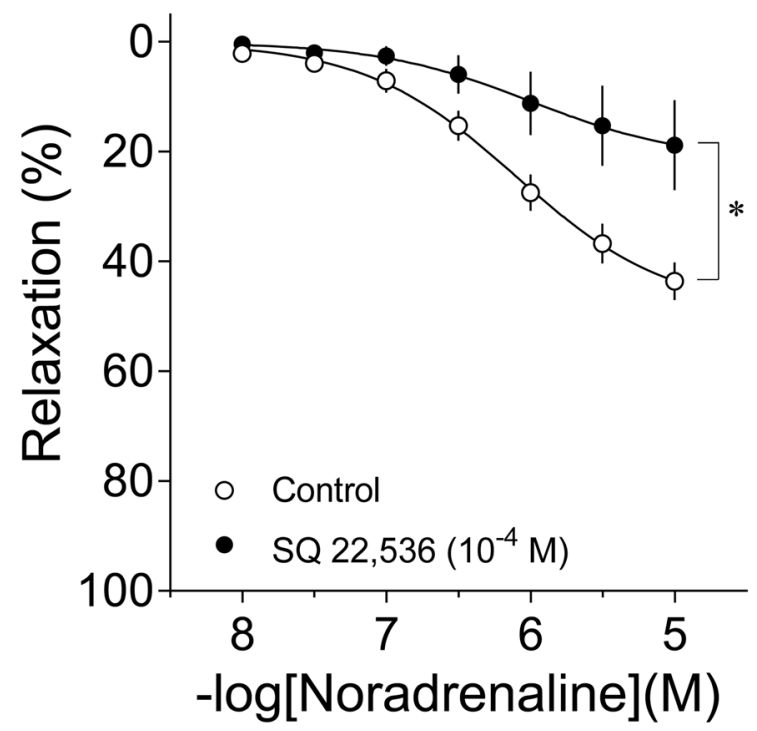

Fig. 6. Effects of SQ 22,536 on NA-induced relaxation in segments of the rat aorta ( $n=5$ for each). $* P$ $<0.05$ vs. control.

\section{Discussion}

In this study, we attempted to determine the $\beta$-AR subtypes that mediate AD- and NA-induced relaxation in rat thoracic aortic smooth muscle and to examine the role of cAMP in the relaxant responses. As a result, we showed that the main $\beta$-AR subtype involved in AD-induced relaxation is $\beta_{2}$, whereas $\beta_{1}$ is the main subtype in NA-induced relaxation. Furthermore, assuming that SQ 22,536 is a highly selective inhibitor of adenylyl cyclase, both $\beta_{2}$-AR-mediated relaxation by AD and $\beta_{1}$-AR-mediated relaxation by NA are dependent on cAMPmediated mechanisms.

A novel aspect of this study is the detection of $\beta$-AR-mediated relaxant responses to endogenous catecholamines in the thoracic aortic smooth muscle of the rat. Although some studies have previously described $\beta$-AR-mediated relaxation of vascular smooth muscle induced by endogenous catecholamines $(12,13,15,16)$, the extent of relaxation reported was generally smaller than that in our study. AD or NA causes a strong contractile response rather than relaxation in thoracic aortic smooth muscle, suggesting that the expression density of $\beta$-ARs is lower than that of contractile $\alpha_{1}$-ARs, even though $\beta$-ARs are present. Therefore, in order to detect the relaxant responses mediated through $\beta$-AR, it is necessary to ensure that the contribution of $\alpha_{1}$-ARs is negligible or very low. In this study, we therefore used a high concentration $\left(10^{-5} \mathrm{M}\right)$ of the selective $\alpha_{1}$-AR agonist Phe as a contractile stimulant to detect significant relaxant responses due to AD or NA. In other words, we speculated that only the $\beta$-AR-mediated relaxant component in response to AD or NA would be detected pharmacologically when the $\alpha_{1}$-AR-mediated contractile component was excluded, since $\alpha_{1}$-AR activation is saturated by the maximum contraction in response to a high concentration $\left(10^{-5} \mathrm{M}\right)$ of Phe. Therefore, we de- 
cided to determine which $\beta$-AR subtypes mediate vascular relaxation induced by endogenous catecholamines using this approach.

First, we determined the $\beta$-AR subtypes and role of cAMP in AD-induced relaxation. Functional experiments showed that the main $\beta$-AR subtype that triggers AD-induced relaxation was $\beta_{2}$, although $\beta_{1}$ could also contribute slightly to the relaxant responses induced by higher concentrations of AD. Measurement of tissue cAMP content showed that increasing effects of AD on tissue cAMP content were mediated mainly through $\beta_{2}$-AR, although $\beta_{1}$-AR might contribute faintly to these effects. Therefore, the results of the tissue cAMP measurements were found to correlate with those of the functional experiments.

Next, we determined the $\beta$-AR subtypes and role of cAMP in NA-induced relaxation. NA, a sympathetic neurotransmitter, is generally recognized as a selective $\beta_{1}$-AR agonist, but few studies to date have reported blood vessel relaxation induced by NA $(12,13)$. In addition, $\beta$-AR subtypes responsible for NA-induced relaxation appear to vary by species. For example, the $\beta$-AR subtype that mediates NA-induced relaxation in the coronary arteries of dogs is $\beta_{1}$ (12), whereas in human coronary arteries, it is the $\beta_{2}$ subtype (13).

However, we showed that the $\beta$-AR subtype that mediates NA-induced relaxation in rat thoracic aorta is predominantly $\beta_{1}$, since the relaxant response was almost completely suppressed by propranolol $\left(10^{-7} \mathrm{M}\right)$ and strongly suppressed by atenolol $\left(10^{-6} \mathrm{M}\right)(17)$. The present results are also consistent with those of our previous study; NA-induced relaxation was largely unaffected by ICI-118,551 $\left(10^{-8} \mathrm{M}\right)$, but was almost completely inhibited by combined treatment with atenolol $\left(10^{-6} \mathrm{M}\right)$ plus ICI-118,551 $\left(10^{-8} \mathrm{M}\right)$ (Fig. 4). Furthermore, the NA-induced increase in tissue cAMP content was found to be strongly suppressed by atenolol $\left(10^{-6} \mathrm{M}\right)$ (Fig. 5 ), thus indicating the important role of $\beta_{1}$-AR and supporting the results of the functional experiments.

However, the effect of ICI-118,551 on the NA-induced increase in tissue cAMP content differed from what was expected following its effect on NA-induced relaxation; in the presence of ICI-118,551 $\left(10^{-8} \mathrm{M}\right)$, the NA-mediated increase in tissue cAMP content was only approximately $35 \%$, thus indicating a degree of suppression of approximately $65 \%$ (Fig. 5). However, since ICI-118,551 at $10^{-8} \mathrm{M}$ selectively inhibits $\beta_{2}$-AR without showing antagonistic effects against $\beta_{1}$-AR (7), we cannot provide a rational explanation against these contradictory results. A likely interpretation of the different effects of ICI-118,551 on the relaxant response vs. cAMP contents may be that ICI-118,551 acts as an inverse agonist for $\beta_{2}$-AR (18). If the assumption that ICI118,551 is an inverse agonist is correct, ICI-118,551 should reduce the basal level tissue cAMP content. Indeed, our unpublished observation indicated that ICI-118,551 $\left(10^{-8} \mathrm{M}\right)$ decreased the basal level tissue cAMP content from $1.65 \mathrm{pmol} / \mathrm{mg}$ protein to $1.30 \mathrm{pmol} / \mathrm{mg}$ protein $(n=2)$. Therefore, NA-induced increase in cAMP content in the presence of ICI-118,551 $\left(10^{-8} \mathrm{M}\right)(\mathrm{ICI}+\mathrm{NA}$; Fig. 5) should be strictly compared with that in the presence of ICI-118,551. However, as shown in Fig. 5, NA-induced increase in cAMP content in the presence of ICI118,551 (ICI + NA) was compared with the basal level cAMP content in the absence of ICI-118,551. As a result, NA-induced increase in cAMP content in the presence of ICI-118,551 $\left(10^{-8} \mathrm{M}\right)(\mathrm{ICI}+\mathrm{NA})$ was estimated to be smaller than the expected increase by NA, and the inhibitory effect of ICI-118,551 might be judged apparently significant. An alternative explanation for the different effects of ICI-118,551 on the relaxant response vs. cAMP contents is the possible participation of a cAMP-independent mechanism in NA-induced relaxation. Further studies are needed to elucidate this issue in detail.

These observations are consistent with the efficacy ranking of catecholamines, whereby AD is several times more potent than NA against $\beta_{2}$-ARs, while the potencies of AD and NA against $\beta_{1}$-ARs are comparable (4). As we conclude, the present study did not show a substantial contribution of propranolol-insensitive $\beta$-AR $\left(\beta_{3}-\mathrm{AR}\right)$ to $\mathrm{AD}$ - and NA-mediated relaxant responses, at least in the concentration ranges used in the present study. 
Our functional experiments showed that both $\beta_{1}$-AR and $\beta_{2}$-AR expressed in rat thoracic aortic smooth muscle functioned as the relaxant receptors for endogenous catecholamines $\left(\beta_{1}\right.$-AR for NA and $\beta_{2}$-AR for AD). Furthermore, since both $\beta_{1}$-AR-mediated relaxations to NA and $\beta_{2}$-AR-mediated relaxations to AD were potently inhibited by SQ 22,536 $\left(10^{-4} \mathrm{M}\right)$, these relaxant responses were suggested to be strongly dependent on cAMP-mediated mechanisms. However, NA and AD are susceptible to degradation by metabolic enzymes such as monoamine oxidase (MAO) or catechol- $O$-methyltransferase (COMT) and are readily inactivated through reuptake mechanisms. Therefore, it is possible that the inhibitory effects of SQ 22,536 on these catecholamines were somewhat exaggerated. However, the inhibitory effects of SQ 22,536 on AD- and NA-mediated relaxation were also preserved in the presence of the following inhibitors: $\mathrm{MAO}_{\mathrm{A}}$ inhibitor clorgiline $\left(10^{-5}\right.$ M), COMT inhibitor Ro 41-0960 $\left(10^{-5} \mathrm{M}\right)$, uptake 1 inhibitor desipramine $\left(3 \times 10^{-7} \mathrm{M}\right)$, and uptake 2 inhibitor deoxycorticosterone $\left(10^{-5} \mathrm{M}\right)$ (data not shown). Therefore, the possible involvement of metabolic pathways of $\mathrm{AD}$ and NA can be eliminated when interpreting the suppressive effect of SQ 22,536 on the effects of these catecholamines. However, it should be noted that the conclusion that both $\beta_{1}$-AR-mediated relaxation by NA and $\beta_{2}$-AR-mediated relaxation by AD are strongly dependent on cAMP is significant only when SQ 22,536 $\left(10^{-4} \mathrm{M}\right)$ is a selective inhibitor of adenylyl cyclase. Furthermore, the possible contribution of $\alpha_{2}$-AR to the cAMP increasing and aortic relaxant effects of AD and NA should be considered since stimulation of $\alpha_{2}$-AR, which is a $\mathrm{G}_{\mathrm{i}}$-coupled receptor, inhibits tissue cAMP content elevation and its relaxation.

Finally, we describe the possibility that $\beta_{3}$-ARs, which are also likely to be expressed in the rat aorta, function as physiological $\beta$-ARs against endogenous catecholamines. First, we speculate that $\beta_{3}$-ARs are present in aortic smooth muscle of the rat based on the relaxation induced by the $\beta_{3}$-AR partial agonist CGP-12177A (17). Furthermore, Horinouchi et al. suggested that $\beta_{3}$-AR mediates the relaxation induced by endogenous catecholamines (NA, AD, and dopamine) in digestive tract smooth muscle tissues including guinea-pig stomach fundus, duodenum, and taenia caecum $(19,20)$. However, we could not present experimental evidence to suggest a significant contribution of $\beta_{3}$-AR to the relaxant responses induced by AD and NA in the rat aorta because these responses were completely suppressed by propranolol or the combination treatment of atenolol and ICI-118,551. Furthermore, we could not demonstrate that dopamine induces relaxation in Phe-contracted rat aorta segments (data not shown). Therefore, we concluded that the contribution of $\beta_{3}$-AR is insubstantial in endogenous catecholamine-mediated relaxation in rat aorta, or could not be detected using our experimental conditions.

In summary, we have shown that $\beta_{1}$-AR and $\beta_{2}$-AR in the rat thoracic aortic smooth muscle function are stimulated by NA and AD, respectively, and that the subsequent relaxant responses are strongly mediated through cAMP-dependent mechanisms.

\section{Acknowledgments}

Shunsuke Shiina is financially supported in part by a Nagai Memorial Pharmaceutical Research Encouragement Award. We would like to thank Editage (www.editage.jp) for English language editing.

\section{Competing interests}

The authors declare that they have no competing interests. 


\section{References}

1. Nagatomo T, Koike K. Recent advances in structure, binding sites with ligands and pharmacological function of $\beta$-adrenoceptors obtained by molecular biology and molecular modeling. Life Sci. 2000; 66(25): 2419-26.

2. Alexander SP, Mathie A, Peters JA. Guide to Receptors and Channels (GRAC), 5th edition. Br J Pharmacol. 2011; 164 (Suppl 1): S1-324. [Medline] [CrossRef]

3. Allwood MJ, Cobbold AF, Ginsburg J. Peripheral vascular effects of noradrenaline, isopropylnoradrenaline and dopamine. Br Med Bull. 1963; 19: 132-6. [Medline] [CrossRef]

4. Tank AW, Lee Wong D. Peripheral and central effects of circulating catecholamines. Compr Physiol. 2015; 5(1): 1-15. [Medline] [CrossRef]

5. Lands AM, Arnold A, McAuliff JP, Luduena FP, Brown TG. Differentiation of receptor systems activated by sympathomimetic amines. Nature. 1967; 214(5088): 597-8. [Medline] [CrossRef]

6. Rozec B, Noireaud J, Trochu JN, Gauthier C. Place of beta 3-adrenoceptors among other beta-adrenoceptor subtypes in the regulation of the cardiovascular system. Arch Mal Coeur Vaiss. 2003; 96(9): 905-13. [Medline]

7. Tanaka Y, Matsushita M, Tamura K, Kogo H, Koike K. The $\beta$-adrenoceptors in blood vessels: recent knowledge on the vascular smooth muscle receptor subtypes that mediate blood vessel relaxation and the role of endothelium. Curr Top Pharmacol. 2006; 10: 33-42.

8. Brawley L, Shaw AM, MacDonald A. $\beta_{1^{-}}, \beta_{2^{-}}$and atypical $\beta$-adrenoceptor-mediated relaxation in rat isolated aorta. Br J Pharmacol. 2000; 129(4): 637-44. [Medline] [CrossRef]

9. Matsushita M, Horinouchi T, Tanaka Y, Tsuru H, Koike K. Characterization of $\beta_{3}$-adrenoceptormediated relaxation in rat abdominal aorta smooth muscle. Eur J Pharmacol. 2003; 482(1-3): 235-44. [Medline] [CrossRef]

10. Flacco N, Segura V, Perez-Aso M, Estrada S, Seller JF, Jiménez-Altayó F, Noguera MA, D’Ocon P, Vila E, Ivorra MD. Different $\beta$-adrenoceptor subtypes coupling to cAMP or NO/cGMP pathways: implications in the relaxant response of rat conductance and resistance vessels. Br J Pharmacol. 2013; 169(2): 413-25. [Medline] [CrossRef]

11. Matsushita M, Tanaka Y, Koike K. Studies on the mechanisms underlying $\beta$-adrenoceptor-mediated relaxation of rat abdominal aorta. J Smooth Muscle Res. 2006; 42(6): 217-25. [Medline] [CrossRef]

12. Shiraishi S, Okamura T, Toda N. $\beta_{1}$-Adrenoceptor-mediated relaxation by norepinephrine in dog hepatic arteries. Jpn J Pharmacol. 1997; 73(1): 101-3. [Medline] [CrossRef]

13. Sun D, Huang A, Mital S, Kichuk MR, Marboe CC, Addonizio LJ, Michler RE, Koller A, Hintze TH, Kaley G. Norepinephrine elicits $\beta_{2}$-receptor-mediated dilation of isolated human coronary arterioles. Circulation. 2002; 106(5): 550-5. [Medline] [CrossRef]

14. Matsumoto T, Wakabayashi K, Kobayashi T, Kamata K. Functional changes in adenylyl cyclases and associated decreases in relaxation responses in mesenteric arteries from diabetic rats. Am J Physiol Heart Circ Physiol. 2005; 289(5): H2234-43. [Medline] [CrossRef]

15. Zuberbuhler RC, Bohr DF. Responses of coronary smooth muscle to catecholamines. Circ Res. 1965; 16: 431-40. [Medline] [CrossRef]

16. Mekata H, Niu H. Electrical and mechanical responses of coronary artery smooth muscle to catecholamines. Jpn J Physiol. 1969; 19(5): 599-608. [Medline] [CrossRef]

17. Shiina S, Ui R, Endo T, Obara K, Chino D, Tanaka Y. The nitric oxide-cGMP pathway does not play an essential role in $\beta$-adrenoceptor-mediated smooth muscle direct relaxation in the rat thoracic aorta. Toho J Med. 2016; 2(3): 95-105.

18. Bond RA, Leff P, Johnson TD, Milano CA, Rockman HA, McMinn TR, Apparsundaram S, Hyek MF, Kenakin TP, Allen LF, Lefkowitz RJ. Physiological effects of inverse agonists in transgenic mice with 
myocardial overexpression of the $\beta_{2}$-adrenoceptor. Nature. 1995; 374(6519): 272-6. [Medline] [CrossRef]

19. Horinouchi T, Koike K. Characterization of atypical $\beta$-adrenoceptors in the guinea pig duodenum. Eur J Pharmacol. 1999; 376(1-2): 61-6. [Medline] [CrossRef]

20. Horinouchi T, Koike K. Pharmacological analysis of atypical $\beta$-adrenoceptors in the guinea pig gastric fundus using the $\beta_{3}$-adrenoceptor antagonist bupranolol. Pharmacology. 1999; 59(6): 290-7. [Medline] [CrossRef] 